\title{
Teaching practice and reform of the cultivation of excellent engineer based on the idea of engineering education
}

Hanxin Shen, Feibing Xiong, Zhangchao Huang, Zijun Bai

Hanxin Shen, Feibing Xiong, Zhangchao Huang, Zijun Bai, "Teaching practice and reform of the cultivation of excellent engineer based on the idea of engineering education," Proc. SPIE 10452, 14th Conference on Education and Training in Optics and Photonics: ETOP 2017, 1045231 (16 August 2017); doi: 10.1117/12.2269924

Event: 14th Conference on Education and Training in Optics and Photonics, ETOP 2017, 2017, Hangzhou, China 


\title{
Teaching Practice and Reform of the Cultivation of Excellent
}

\section{Engineer Based on the Idea of Engineering Education}

\author{
Hanxin Shen, Feibing Xiong, Zhangchao Huang, Zijun Bai \\ School of Opto-Electronic and Communication Engineering, Xiamen University of Technology, Xiamen, Fujian \\ 361024
}

\begin{abstract}
How to realize the joint cultivation of excellent engineer for the school and the enterprise is an important task of the project of excellent engineers. In five years of teaching practice, based on the concept of engineering education certification, through target management of school and enterprise, cultural fusion, stage implementation and feedback, excellent engineer education training plan of opto-electronic specialty is being implemented. It standardizes the specialty construction and practice and explores new teaching management mode, which gets the recognition of graduates and enterprises and achieves a win-win situation for school and enterprise.
\end{abstract}

Key words: Optoelectronic Information Science and Engineering; Excellent engineer; Practice teaching; School enterprise cooperation

\section{Introduction}

At present, the economic and social development puts forward new requirements for the professionalism and skills of high quality talents. The applied universities need to seize the opportunity of the construction of engineering accreditation system and deepen the reform and innovation of training mode of applied excellent engineer. Therefore, based on a correct understanding of the connotation of specialty certification standards of engineering education, leading professional construction and education reform by specialty certification and pushing forward the reform exploring of the construction of engineering education accreditation system in applied university are very important. It can further promote the teaching reform of high school, improve the level of specialty construction and the quality of personnel cultivation and cultivate applied engineering and technical personnel with "excellent engineer quality".

"Excellent engineer education cultivation program" (referred to as the "excellent program") is a national policy whose goal is to cultivate social needed talents. An important teaching part of excellent program is the training of practical ability of students. A lot of colleges and universities carry out the teaching practice of excellent engineers with their own characteristics ${ }^{[1-5]}$.

Optoelectronic information science and engineering specialty of Xiamen University of Technology has been the pilot specialty of excellent program. Therefore, to conform to the development of the application oriented connotation construction of Xiamen University of Technology, we analyze the problems of traditional teaching mode, explore and construct actively engineering education accreditation system, implement excellent engineer education cultivation 
program, and put forward and implement the corresponding teaching practice plan.

\section{Introducing engineering education into excellent program}

To implement the "National long-term education reform and development plan (2010-2020)", the Ministry of Education held a start meeting of "excellent program". "Excellent program" takes cultivating the engineering and technical personnel of high quality as its goal so that it has a complementary close relationship with "engineering education specialty certification"(referred to as "engineering certification"). In 2006, national engineering education specialty certification expert committee was established. In order to be in line with international engineering education, achieve mutual authentication between the international engineering education, enhance the international competitiveness of engineering and technical personnel, China successfully joined the Washington Accord in June 2013. In the current standard of engineering certification, certificated specialties have covered 15 categories, including machinery, electronic information and electrical engineering. It has laid a solid foundation for engineering education standardization and internationalization. Specialty certification has become one of the key work to carry out teaching evaluation and improve the teaching quality in our country at present. Therefore, in the process of implementing the plan, referring to the standard of engineering certification can complement and improve the cultivation goal and plan.

Compared with the traditional teaching philosophy, engineering certification praises highly Outcomes-Based Education (abbreviated as OBE). OBE education philosophy puts more emphasis on the student's learning results. According to the results, teaching activities and evaluation criteria are designed which change the traditional mode of mainly giving a lecture by teachers. Therefore, introducing the engineering education concept of OBE can solve many problems in the implementation of "excellent program", and change the traditional teaching method of instilling and imparting. It takes students as the center and puts more emphasis on the ability of graduates.

\section{Difficulties in the implementation of "excellent program"}

Excellent program is a guiding plan for the purpose of training engineering talents. For a long time, we pay too more attention to knowledge imparting and theory teaching and ignore the practice teaching. The practice teaching is fragmented, which has less teaching hours and simplified content. It directly affects the students' innovative ability and practical skills. Though revising the cultivation plan and practicing teaching, there are some problems in the cultivation mode of "excellent program" in the specialty of opto-electronic information science and engineering.

(1) The program's form is constructed but the content is not clear. Though the cultivation plan is written into the teaching program, the details of the plan are not well implemented in the actual teaching because the teachers are not clear about the cultivation mode of "excellent program". The 
teaching method follows the cultivation mode of common class, in which the theory teaching is paid more attention to and the practice teaching less attention. There is still a certain distance from the goal in the improvement of the ability of engineering practice.

(2) The students don't actively learn knowledge and don't have a clear direction of study. It is mainly reflected in the students' misunderstanding of "excellent program". They often think that the cultivation mode of excellent engineer is the same as the mode of key class in high school, in which students with good grades should be selected into "excellent program". As for the quality of "excellent engineer", they are not clear about it. Therefore, that they are lack of motivation to learn actively increases our cultivation difficulty.

(3) The curriculum is not reasonable and the engineering practice course is little. Under the limit of the number of double-qualified teachers and practice sites, there are too many theory courses in the cultivation plan, which doesn't highlight the characteristics of opto-electronic specialty of emphasizing practice ability and operation skills. At present, only some practice courses have been modified in the cultivation plan. However, the theory courses can't well realize the goal of emphasizing practice ability in their teaching schedule. Therefore, there are many unreasonable factors that need to be improved and perfected in the arrangement of the theory and practice courses. It needs to increase the number of the courses that are offered by enterprise mentors.

(4) The content of enterprise practice teaching is not well implemented. The enterprise practice teaching is a key step of talents cultivation of "excellent program", however, there are many shortcomings in this step for opto-electronic information and other specialties. Related enterprises only allow students to engage in the work of ordinary workers, not regard them as up-coming engineers. The enthusiasm of cultivating students for enterprise is not high and the effort expended by enterprises and the conditions prepared are seriously inadequate.

\section{Thinking and practice on the teaching reform of "excellent}

\section{program"}

(1) Reform and improve cultivation plan of "excellent program" and build the education cultivation system of opto-electronic specialty which meets the needs of Xiamen's opto-electronic industry and engineering education specialty certification.

Strictly referring to the general standard of engineering education specialty certification and focusing on the goal of excellent engineer cultivation, we will carry out reform and exploration in the aspects of aim positioning of cultivating, implementation of cultivation plan, students' academic guidance, teaching administration system and quality control system. Therefore, from the multiple dimensions of the knowledge, the quality and the ability of excellent engineer, we will further refine the talent cultivation goal, reconstruct the curriculum system and teaching content and strengthen the cultivation of students' engineering consciousness and quality, based on the specialty norms and the standard of engineering education specialty certification issued by 
teaching guiding committee of Ministry of Education. We will realize the full participation of students in engineering practice and innovation training activities and four-year continuous training of engineer quality, through the teaching parts of specialty courses, summer training, specialty practice, graduation thesis and the innovation and practice program of specialty competition and college students' scientific research innovation plan. Then, the sustainable engineering education specialty certification system for opto-electronic specialty in applied universities could be constructed.

(2) Investigate and construct the practice teaching system suitable for the standard of engineering education specialty certification and the quality requirement of excellent engineer in "excellent program"

We will investigate and optimize the group of specialty core supporting courses, According to the requirements of talents cultivation in Engineering education specialty certification (ten requirements in knowledge, ability and quality of university students), guided by cultivation plan of excellent engineer, following the basic principles of engineer training and students' cognitive law. And the teaching content of related courses will be overall planned and optimized according to mutual relation of each course. In this way, a complete and reasonable progressive course system could be constructed.

(3) Standard teaching management and do well top-level design

Closely around the theme of improving teaching quality and according to the graduation certification of engineering certification standard and the talents' cultivation standard of "excellent program", we plan to sort out teaching thinking, perfect teaching quality system, strengthen teaching process management and do well top-level design. We will standardize teaching management and do a good job in collecting, filing, and summarizing all kinds of teaching materials in the process of excellent engineer cultivation. It will provide the necessary material for the analysis of school-government-enterprise cooperation to carry out engineering education. At the same time, we plan to complete the analysis of the requirements of the ability for engineering certification and data collection and sorting. According to the survey of graduates, we will establish complete graduates feedback system and external information feedback system, strengthen the investigation of the relation between ability training of engineer technology for students and their employment situation, collect the evaluation and suggestion of enterprise for the students and our cultivation plan, adjust and improve our cultivation plan system.

(4) Strengthen school-enterprise cooperation and jointly build a joint cultivation mode for excellent engineer for engineering education certification

It is necessary to give full play to the government, universities and society to the cultivation of excellent engineers, absorb experts of enterprise and industry to join the specialty teaching guidance committee. They can participate in making specialty development schedule, setting specialty cultivation goal and plan. It needs to vigorously promote enterprises, scientific research institutions and colleges and universities to build students' innovation practice employment base, innovation laboratory, research platform, gradually expand the graduation design proportion which are combined with the industry and the enterprises, pay attention to the participation and directing 
of the enterprise engineer in teaching sections. We will select outstanding students to enter the school and enterprise cooperation innovation practice platform to carry out the engineering practice and project development. It can enable students to concern at important problems and actual needs of enterprises and industry in the process of engineering practice. Referring to the needs of enterprise and industry, we will re design personnel cultivation quality evaluation system, so that it can meet the needs of enterprises and industries in the new period. We will steadily promote the quality evaluation monitoring system in an out of school, and actively explore new modes of excellent engineers' cultivation in applied university.

\section{Summary}

According to the requirements of the enterprise and the industry, referring to the engineering certification standards, on the basis of the goal of excellent engineer project, the key problems are solved as follows:

(1) According to different social needs of the applied undergraduate school, it needs to classify the students of opto-electronic engineering specialty, to make different cultivation plans and the corresponding ability correlation matrixes and implementation paths.

(2) According to cultivation goal and graduation requirement, it needs to optimize the curriculum system, reform the teaching content and methods. It will achieve the seamless connection between personnel cultivation and enterprise demand.

(3) Guided by the cultivation of applied excellent engineer, we would innovate the teaching elements of "new curriculum, new teaching materials, new methods, and new platform". It needs to enhance the quality courses, create the network teaching, flip classroom teaching mode, and improve the cultivation mode.

In short, we will combine "excellent program" of opto-electronic specialty with the engineering education certification. Through the construction of application-oriented undergraduate engineering education accreditation system and the full participation of university, Secondary College, teachers, students, we will standardize the construction and the practice of the specialty, refine new teaching management mode so as to implement the thought of "practice, innovative talent cultivation system guided by employment demand and quality cultivation".

\section{ACKNOWLEDGMENT}

This paper is supported by the Teaching and Research Social Science Program of Young Teachers of Fujian Province (JAS151306), Hot and Difficult Point Teaching Program of National University Opto-electronic Specialty Education and the education reform program of the exploration on the academic early warning and support mechanisms for science and engineering students (JGY201511).

\section{REFERENCES}

[1] L.Q. Feng, D.L. H, W.H Li, Z.D. K and K.K. Zeng, "Study on Practical Innovation Ability 
Cultivation of Management Postgraduates Based on QFD," Education Journal, vol. 5, No. 5, 2016, pp. 113-120.

[2] J.F. Luo. Study on College Enterprise Education from the Perspective of Collaborative Innovation. Science Journal of Education.Vol. 4, No. 5, 2016, pp. 145-148.

[3] Y.F. Wei, Z. Zheng, Y.H. Wu, and X.G. Yin. Talent Cultivation of Excellent Engineer Training Plan in Henan Polytechnic University. Science Journal of Education. Vol. 2, No. 4, 2014, pp. 96-100.

[4] R. A. Kareem. The Effect of Using Wood's Model in Systemic Thinking Skills Among Students in Second Grade Intermediate in Mathematics. Science Journal of Education. Vol. 4, No. 5, 2016, pp. 149-158

[5] C.H. He, H.Y. Zhang and A.X. Wei, "Exploration and Practice of the Practical Teaching Curriculum System for Cultivating Applied and Innovative Undergraduate Talents," Creative Education. vol. 3,2012, pp. 181-184. 